\title{
Aa. Vv., Libertinage et politique au temps de la monarchie absolue
}

Daniela Dalla Valle

\section{(2) OpenEdition}

1 Journals

\section{Edizione digitale}

URL: http://journals.openedition.org/studifrancesi/27501

DOI: 10.4000/studifrancesi.27501

ISSN: 2421-5856

\section{Editore}

Rosenberg \& Sellier

\section{Edizione cartacea}

Data di pubblicazione: 31 décembre 2006

Paginazione: 596

ISSN: 0039-2944

\section{Notizia bibliografica digitale}

Daniela Dalla Valle, « Aa. VV., Libertinage et politique au temps de la monarchie absolue », Studi Francesi [Online], 150 (L | III) | 2006, online dal 30 novembre 2015, consultato il 08 novembre 2020. URL : http:// journals.openedition.org/studifrancesi/27501; DOI : https://doi.org/10.4000/studifrancesi.27501

Questo documento è stato generato automaticamente il 8 novembre 2020.

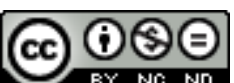

Studi Francesi è distribuita con Licenza Creative Commons Attribuzione - Non commerciale - Non opere derivate 4.0 Internazionale. 


\title{
Aa. Vv., Libertinage et politique au temps de la monarchie absolue
}

\author{
Daniela Dalla Valle
}

\section{NOTIZIA}

Libertinage et politique au temps de la monarchie absolue, "Littératures classiques", 55, été 2005, pp. 304.

1 Questo numero di "Littératures classiques", diretto da Jean-Charles Darmon e da Georges MoLiNiÉ, è l'esito rimaneggiato del colloquio dallo stesso titolo che si svolse al Castello di Versailles e a Paris-Sorbonne nel settembre 2002. Esso si propone - come è annunciato nell'Introduction di J.Ch. DARMON, di far emergere un certo numero di elaborazioni teoriche specifiche all'interno di un corpus definito "libertino", di differenziare le situazioni successive del libertinaggio nel campo delle pratiche sociopolitiche della monarchia assoluta, e di verificare l'imponente rinnovamento delle ricerche sul libertinaggio da Pintard in poi. Un secondo intervento introduttivo è affidato a G. Molinié, che brevemente si sofferma sugli enjeux du libertinage.

2 Gli articoli raccolti sono suddivisi in due parti: in primo luogo, nove studi prevalentemente filosofico-politici - sono riuniti sotto il titolo Thématiques et enjeux spécifiques de la critique libertine: entre conformisme apparent et subversion radicale. J. P. CAVAILLÉ si sofferma sull'impostura politica delle religioni e la saggezza libertina, S. GOUVERNEUR studia La Mothe Le Vayer e Samuel Sorbière, S. GIOCANTI analizza il rapporto fra il libertinaggio politico e lo scetticismo, Fr. GaBRIEL confronta libertinaggio e gallicanesimo, A. MCKENNA e E. MÉCHOULAN si orientano su Pascal, G. PAGANINI su Spinoza, G. ARTIGAS-MENANT sui manoscritti filosofici clandestini, J. DAGEN su Fontenelle.

3 Sei articoli, in cui prevale la dimensione letteraria, sono inseriti nella seconda parte, intitolata Modalités et effets de l'art d'écrire libertin: d'un genre à l'autre, d'un siècle à l'autre. I. MOREAU ritorna, da un punto di vista diverso, su La Mothe Le Vayer, M. JEANNERET si occupa di erotismo e libertinaggio nel XVII secolo, M. RoselLINI s'interroga sulla 
"générosité" dell'eroe libertino, J.Ch. DARMON confronta La mort d'Agrippine e L'Autre Monde di Cyrano, S. HOUDARD si occupa di Mme de Villedieu e J.GOLDZINK arriva al romanzo libertino settecentesco.

4 Come Annexe è inserito un testo di Gassendi, De la justice, du droit et des lois, tratto dal Syntagma philosophicum, presentato da J. Ch. DARMON, tradotto da J. M. CIVARDI e annotato da entrambi gli studiosi. 